\title{
The key enabling criteria of e-entrepreneurship evolving practices and implementation in Saudi Arabia
}

\author{
Ikhlas F. Zamzami ${ }^{1}$
}

Received: 19 December 2020 / Accepted: 30 June 2021 / Published online: 24 August 2021

(c) The Author(s), under exclusive licence to Springer Nature Switzerland AG 2021

\begin{abstract}
Businesses that are entirely conducted online have achieved tremendous success. The system has improved to provide a path for the development of online entrepreneurship where individuals can become founders of online businesses or manage internet-based businesses. There are many research studies from different contexts to understand the importance of E-Entrepreneurship. Unfortunately, not until recently, E-Entrepreneurship business impact and opportunities were not being seriously discussed. Furthermore, the complexity and dynamic flow-process towards adopting E-Entrepreneurship were also ignored. As a result, this study is aimed at examining the adoption of E-Entrepreneurship among Saudi Arabians. Four main variables were conceptualized, "E-entrepreneurship behavioral intention (EBI)", "perceived usefulness (PU)", "social pressure (SP)", and "online transactions (OT)". Quantitative surveys were utilized to test the proposed hypothesis. Furthermore, DEMATEL evaluation analysis was used to find the most important criteria of E-Entrepreneur adoption. The samples of the study are obtained from Saudis. Analysis of the results revealed that all the hypotheses are positively significant and supported. This indicates the influences of all the variables on E-Entrepreneurship Behavioral Intention. DEMATEL results are also consistent with the survey finding. It indicates that "social pressure" in E-Entrepreneurship adoption is the key criteria. The study reveals the important factors that affect E-Entrepreneurship acceptance in Saudi Arabia. The finding of the study significantly implicates E-Entrepreneurship service providers and e-marketers to develop a more complete understanding of the factors that affect the Individual intention to accept E-Entrepreneurship in Saudi Arabia.
\end{abstract}

Keywords E-Entrepreneurship · Online transactions $\cdot$ Perceived usefulness $\cdot$ Social pressure

Ikhlas F. Zamzami

ifzamzami@kau.edu.sa

1 Management Information System Department, Business College, King Abdul-Aziz University, Rabigh, Saudi Arabia 


\section{Introduction}

E-Entrepreneurship is defined in a variety of ways. E-Entrepreneurship, according to Kollmann (2014), is the act of "establishing a new company with a creative business concept within the Net Economy, which offers its goods and/or services based on a purely electronic production of value, using an electronic platform in data networks." Essentially, the advancement of information technology was the only thing that enabled this value offer to be made. "Founder or Manager of an Internet-based business" is another term for an Internet entrepreneur (Abubakar et al. 2017). Unlike several aspects of online business, where people engaged in different forums for purchasing and selling, E-Entrepreneurship allows individuals to use a variety of platforms, from the web to mobiles, to connect with online communities to improve business transactions. This allows stakeholders to connect online, get input from trusted colleagues, exchange market insights, and get price discounts on customdesigned goods (Friedrich 2015).

E-Entrepreneurship has radically changed the way both producers and consumers make decisions by being a revolutionary business concept within the business mind of society. It has resulted in the development of a digital business network and a revolutionary business concept focused solely on online resources. Essentially, the advancement of information technology was the only thing that enabled this value offer to be made. There are numerous research studies from various contexts to understand the value of E-Entrepreneurship. However, until recently, the market effects and opportunities of E-Entrepreneurship were not seriously addressed. Furthermore, E-dynamics Entrepreneurship's and dynamic flow-process were overlooked. Businesses that are completely executed on the Internet have had a lot of success, and now the infrastructure has improved to provide a direction for the growth of online entrepreneurship where individuals can be the creators of online businesses or manage them. As a result, the E-Entrepreneurship network encourages people to engage in Internet-based businesses.

Some of the first e-commerce companies, including eBay and Amazon, have shifted their focus to E-Entrepreneurship. Some researchers suggest that today's potential customers are more conscious of seeking other people's advice before making a buying decision, rather than relying solely on product knowledge provided by online vendors. E-Entrepreneurship is becoming increasingly important in today's market environment. Many businesses are attempting to introduce E-Entrepreneurship these days (Dayal 2016). As a result, understanding how people embrace E-Entrepreneurship is important, and with the growing importance of E-Entrepreneurship as a mode of business, it's also important to recognise the major factors that influence its adoption.

This study adds to the body of knowledge about Saudi Arabia's E-Entrepreneurial status. The study examines the E-Entrepreneurship network which encourages people to engage in the development of new business models. It is critical to ensure that the required requirements are met to increase the adoption of E-Entrepreneurship as a business model, as well as to recognise the significant factors that influence its acceptance. As a result, the research uncovers the critical factors that influence 
E-Entrepreneurship acceptance in Saudi Arabia. The study's findings have important implications for E-Entrepreneurship service providers and e-marketers who want to gain a better understanding of the factors that influence people's willingness to consider E-Entrepreneurship. The research also provides evidence for how companies can influence the E-Entrepreneurship platform and vice versa. This will raise awareness of the potential of E-Entrepreneurship among practitioners and stakeholders of the platform. As a result, the aim of this study is to investigate the factors that influence E-Entrepreneurship acceptance in Saudi Arabia.

\section{Related work}

During the ongoing COVID-19 crisis, E-Entrepreneurship is gaining popularity quickly. It is clearly seen as an evolving topic; new businesses with creative business ideas are springing up all the time. The Internet is a must-have for E-Entrepreneurship. "Founder or Manager of an Internet-based business" is another term for an Internet Entrepreneur. Unlike several aspects of online business, where people engaged in different forums for purchasing and selling, E-Entrepreneurship allows individuals to use a variety of platforms; from the web to mobile devices, to connect with online communities to improve business transactions. This allows stakeholders to connect online, get input from trusted colleagues, exchange market insights, and get price discounts on custom-designed goods (Friedrich 2015). Given its growing relevance and rapid functional evolution, the research community is increasingly inclined to investigate the position of significant factors that must be addressed to reap its full benefits (Wang and Zhang 2012; Zhou et al. 2013). The majority of studies on this subject are descriptive and only concentrate on the theoretical foundations, such as its operations, the definition itself and its historical evolution (Kollmann 2014; Zhou et al. 2013), technical features (Curty and Zhang 2013), business models, and design concepts (Kollmann 2014; Zhou et al. 2013; Huang et al. 2013).

The field of "E-Entrepreneurship" has received a lot of attention in E-Entrepreneurship Kollmann's work (2014). Many research studies support the concept of E-Entrepreneurship that has been highlighted by the research work. The relationship between E-Entrepreneurship and e-commerce has been explained in Rahmi et al. (2020) following the work of Kollmann (2014). E-Entrepreneurship can be started with no money, while e-commerce is not possible. According to Asadollahi et al. (2019), the field has spawned a modern paradigm that attempts to define a new position of entrepreneurship in economic development, highlighting that companies such as Amazon.com, Google.com, and eBay.com are no longer just global service providers, but have evolved into E-Entrepreneur platforms. As a result, E-Entrepreneurship is often referred to as a creative technology entrepreneurship that progresses through three stages: an initial "evolutionary" development (infancy and youth), a "revolutionary" (crisis), and a second "evolutionary" (maturity) (Eliakis et al. 2020). Furthermore, individual technical competencies and information technology adoption have been shown to have a substantial effect on E-Entrepreneurship (Ayough et al. 2020). Since E-Entrepreneurship is one of the most common uses of 
the Internet in EU countries (Rusu and Roman), E-Entrepreneurship is one of the most popular uses of the Internet in EU countries (2020).

Previous research studies looked at E-Entrepreneurship adoption from a variety of perspectives. The study by Oumlil and Juiz (2018) on "acceptance of tourism E-Entrepreneurship" found that the most important aspect of the emerging E-Entrepreneurship within tourism is mostly linked to the social status towards women. Similarly, Lai and To (2018) looked into the intentions of young Chinese adults to engage in E-Entrepreneurship. According to the findings, E-Entrepreneurship education is an antecedent of adoption attitudes that are influenced by subjective standards and perceived behavior regulation. However, it was also discovered that people's attitudes toward E-Entrepreneurship had little bearing on their e-entrepreneurship intentions. Women's motivation for E-Entrepreneurship has been found to be fueled by bank financing (Mand et al. 2018). E-Entrepreneurship is a successful forum for creating a partnership between the franchisor and the franchisee, according to others (Chen 2019). The use of E-Entrepreneurship has grown to have a regional influence. Younis et al. (2020) investigate the effects of E-Entrepreneur adoption in Qatar. It was discovered that social and cultural perspectives affect attitudes toward digital entrepreneurship. Though Qatar and Saudi Arabia share a common cultural heritage, this may not be the case in terms of Saudi Arabia's perceived support. Furthermore, Younis et al. (2020) found that perceived obstacles have a close relationship with perceived behavioral regulation in implementing E-Entrepreneurship in Qatar. Ball (2020) investigates the effects of E-Entrepreneurship adoption in Turkey. According to the findings, E-Entrepreneurs' personality characteristics have a major effect on their ability to innovate and pursue E-Entrepreneurship. The study also found that E-Entrepreneurs are more effective in creating innovative products and services because of their ability to recognize new digital innovations for their companies (Abubakar et al. 2015).

\section{Research methodology}

In the context of this study, research methodology refers to two interconnected procedural approaches to solving the problem of E-Entrepreneurship that can be implemented. As a result, the purpose of this study is to look at the key criteria for understanding and identifying the most important factors that influence E-Entrepreneurship acceptance in Saudi Arabia. This study uses a quantitative research methodology that includes a questionnaire survey and DEMATEL evaluations. The reason for selecting these approaches rely mainly on the assumption that knowledge about important criteria for E-Entrepreneur adoption with standardized instruments for collecting data from two different approaches on narrowly defined variables.

Technology acceptance model (TAM), developed by Davis (1989), to measure the human acceptance of technology or information systems, was adopted. The model theorizes that "Perceived Usefulness" can determine an individual's behavior to accept or reject a new technology or information system. That is why this current study adopts this model. 


\section{DEMATEL Research Design}

Making decisions are extremely important. Especially when dealing with E-Entrepreneurship. Many issues may arise when considering the possibility of moving any business online. DEMATEL (Decision Making Trial and Evaluation Laboratory) is an important tool for evaluating the features/criteria needed to make an informed decision about E-Entrepreneurship adoption. This aided the current study in confirming the factors that influence E-Entrepreneurship adoption. That is, after conducting the first round of testing the TAM variables and examining their impact on E-Entrepreneurship adoption. DEMATEL is now using the result in its decisionmaking analysis.

The DEMATEL technique was first proposed by the Battelle Memorial's Geneva Research Centre to study complicated scenarios (both known and unknown) to visualise causal relationships using matrixes or digraphs (Fontela and Gabus 1976). It is thought to be a useful method for identifying cause-and-effect chain components in a complex system (Sheng-Li et al. 2018). Race, hunger, environmental protection, and energy are just a few examples (Fontela and Gabus 1976; Gabus and Fontela 1973). It was created and promoted because it is capable of utilizing scientific research methods that are required to comprehend a specific issue. Typically, a hierarchical structure appears to contribute to the recognition of practical solutions among a variety of options (Farooque et al. 2020).

The method takes into account the characteristics of the features of interest, which are verified by their interdependence and then confirm their relationship. As a result, it will generate useful evidence and visualize the structure of complex causal relationships between features (Rostamnezhad et al. 2020). One of the DEMATEL technique's most important assumptions is that each of the criteria or features can directly influence other criteria, but not itself (Jiang et al. 2020). DEMATEL has been used in previous research in a variety of fields. Business policy application (Wu and Lee 2007), strategic marketing and consumer behavior analysis (Wei et al. 2010), in agriculture applications (Kim 2006), in the design of technology innovation (Lee et al. 2010), for airline safety strategies (Liou et al. 2008), applied to selecting systems strategy (Tsai \& Chou 2009) and for e-learning (Tseng 2009).

The following is a description of DEMATEL's structure and calculation steps:

Step 1: Create strategies for gathering expert opinions: From the scores of the experts' opinions, create a direct-influence (average) matrix. The scores should be derived from the responses of each criterion's direct influence on the other criteria. These responses are on a scale of $0-4$, with 0 denoting no influence, 1 denoting a low level of influence, 2 denoting a medium level of influence, 3 denoting a high level of influence, and 4 denoting a very high level of influence. E-entrepreneurship behavioral intention [EB], perceived usefulness [PU], social pressure [SP], and online transactions [OT] are the constructs that were used for the evaluation. "The extent to which an individual intends to adopt or purchase the technology, system, or product in the future," according to the operational definitions for the criteria "E-Entrepreneurship Behavioral intention" (Venkatesh et al. 2003). The term "perceived usefulness" refers to "the degree to which a person believes that using a specific technology/service will improve his or her performance" (Davis 1989). The perceived pressure to perform a behavior 
that comes from observing what important others say or do is referred to as "social pressure", also known as "subjective norm" (Ajzen and Fishbein 1975). The concept of online transactions is crucial when looking into the adoption of Entrepreneurship or the success of E-Entrepreneurship. E-Entrepreneurship entails the use of online platforms, including social networking platforms, to buy and sell goods (Liang et al. 2011). This DEMATEL questionnaire, which was validated and attached below the survey questionnaire, contains four questions for each of the criteria. Following the data collection, the responses are assessed by determining a relationship between the criteria for mutual influence. As a result, the experts' perceptions of how criteria $i$ influence criteria $j$ are collected in a non-negative matrix (for each expert). Following that, an average relation matrix D was created from all of the experts' responses for all of the criteria that can directly influence other criteria but not themselves. As a result, matrix $D$ is the directinfluence matrix shown below:

$$
D=\left[\begin{array}{ccccc}
0 & \ldots & d_{21} & \ldots & d_{1 n} \\
\vdots & \ddots & \vdots & \vdots & \vdots \\
d_{31} & \vdots & \ddots & \vdots & d_{3 n} \\
\vdots & \vdots & \vdots & \ddots & \vdots \\
d_{n 1} & \ldots & d_{n 3} & \ldots & 0
\end{array}\right]
$$

Step 2: normalization of the direct relation matrix: This step involves normalizing $\mathbf{D}$ (the direct-influence matrix) into zeros and ones, to yield a new matrix called Normalize direct-influence matrix N. Its obtained by using Eqs. (1) and (2):

$$
\begin{gathered}
N \frac{D}{x}, \\
x=\max \left[\frac{1}{\max _{1 \leq i \leq n} \sum_{j=1}^{m}\left|m_{i j}\right|}, \frac{1}{\max _{1 \leq i \leq n \sum_{j=1}^{m}\left|m_{i j}\right|}}\right]
\end{gathered}
$$

Step 3: generation of total relation matrix: This step involves calculating the totalinfluence matrix $\mathbf{T}$ from the normalized direct-influence matrix generated in step 2 . This is carried out by Eq. (3),

$$
E=\lim _{k \rightarrow \infty}\left(N+N^{2}+\cdots+N^{k}\right)=N(I-N)^{-1}
$$

where I is an identity matrix.

Step 4: Generating the rows and columns of matrix: This step generates the rows and columns matrix as $n \times 1$ and $1 \times n$ presentation of the rows and columns vectors of the total relation matrix by Eqs. $(4 a, 4 b)$. If the sum of rows and the sum of columns of matrix $T$ are represented by vectors $\boldsymbol{r}$ and $\boldsymbol{c}$ respectively, where

$$
r=\left[r_{i}\right]_{n \times 1}=\left(\sum_{j=1}^{n} t_{i j}\right)_{n \times 1},
$$

and 


$$
c=\left[c_{j}\right]_{n \times 1}=\left(\sum_{j=1}^{n} t_{i j}\right)_{n \times 1} .
$$

Then the sum $S$ of $r_{i}$ and $c_{j}$ will represent the effects of criteria $i$ on $j$ and if $j=i$, then the sum $S$ will shows the total effects given and received by criteria $i$, whereas the difference shows the net effect by criteria $i$, contributes to the system. However, when it is positive, criteria $\boldsymbol{i}$, is a net cause, whereas when is negative, criteria $\boldsymbol{i}$, is a net receiver.

Step 5: Determine the threshold value: It is necessary to set a threshold value $\alpha$ for explaining the structural relationships among the criteria in other to generate an interaction diagram by using Eq. (5):

$$
\alpha=\sum_{i=1}^{n} \sum_{j=1}^{n} t_{i j} / N,
$$

where $N$ is the number of elements in the matrix that will be computed by the average of the elements in matrix $\mathrm{T}$ to extract some minor effects were necessary. This means that those effects below the threshold value will not be selected for presentation in the impact relationships.

Step 6: Construct the relationship diagram for the cause and effect: The relationship diagram is drawn base on the result of the calculation of the previous stages. Thus the cause and effect are map out to all coordinate sets of the sum the rows and columns which indicate the interactions among the criteria and provide information to judge which are the most important criteria and how its influence others.

\section{Survey research design}

Case studies, experiments, cross-sectional studies, and longitudinal studies are common in social science research. If a proper research design for the study has been established, various qualitative and quantitative data collection methods such as interviews, questionnaires, observations, and record analysis may be used to gather proof. The study design is a blueprint for investigating a specific phenomenon. It's a step-by-step procedure, and the progress of each step is contingent on the success of the previous steps. It is a set of decision-making processes, according to Sekaran (2006), that includes stating problems or asking questions, data collection methods, data interpretation and analysis methods, and investigation reporting methods. According to Creswell (2013), the overall research design is a general strategy that aids in defining the data collection location, formulating research issues, field-related ethical criteria, data collection and analysis procedures, and the research's role during the data collection phase. According to Creswell (2013), the proper research method in most research studies is determined by the research issue, research questions, proposed research model, and hypotheses. According to Cooper and Schindler (2001), there are three styles of research design: (1) exploratory, (2) descriptive, and (3) casual or explanatory design. 
The aim of this study is to investigate, comprehend, and recognise the most important factors that influence user acceptance of E-Entrepreneurship in Saudi Arabia. Furthermore, the study looked at the associations (correlations) between the dependent variable and various independent variables linked to E-Entrepreneurship adoption in order to better understand the causal mechanisms at work. As a result, according to Leedy and Ormrod (2005), research into this form of relationship can be classified as an assessment analysis since it involves testing hypotheses and defining variables in a theoretical context. Furthermore, this study incorporates all three stages of research design: (1) exploratory, (2) descriptive, and (3) casual or explanatory. Exploratory research was used by the Researcher to gather relevant background knowledge about a research issue, identify the research gap and research problem, and establish research hypotheses as a result of a detailed review of related published literature (Churchill 1995). Furthermore, various variables were defined based on a thorough review of related literature as well as previous observational studies to formulate appropriate research hypotheses. As a result, the Researcher devised objectives centred on defining the significant factors influencing E-Entrepreneurship acceptance with the use of an integrated research model.

\section{Conceptualization and development of hypothesis}

The proposed conceptualization of this study is based on Davis' (1989) technology acceptance model, DeLone and McLean's (2004) information system performance model, and Ajzen, Icek's theory of expected action (1991). In order to create relationships among these three hypotheses, four key variables were conceptualized. The independent variable "E-Entrepreneurship Behavioral Intention (EBI)" is taken from the technology adoption model, as is one of the independent variables "Perceived Usefulness (PU)" (Davis 1989). The other independent variable, "Social Pressure (SP)", was taken from the theory of planned behavior (Ajzen 1991), and the mediating variable, "Online Transactions (OT)", came from the information system performance model (DeLone and McLean 2004). The above-mentioned E-Entrepreneurship behavioral aim is tied to determining the degree to which Saudis plan to pursue E-Entrepreneurship. From the viewpoint of an entrepreneur, "E-Entrepreneurship behavioral intention" denotes a willingness to embrace and use the Internet for entrepreneurship. To understand individual purpose, this variable has been used and extensively explored as a dependent variable in many theories and models, such as the technological acceptance model (TAM). As a result, in the proposed research model, the decision to use E-Entrepreneurship as an outcome variable is used to explain how other independent variables such as PU and social pressure, directly and indirectly, influence E-Entrepreneurship acceptance.

In this study, perceived usefulness will be used to determine how much an individual believes that using E-Entrepreneurship will improve their entrepreneurial results. The technology acceptance model (TAM) has PU as one of its core constructs (Davis 1989). PU is relevant in online free enterprise, and it should have a positive effect on the "E-Entrepreneurship Behavioral purpose". Ali et al. (2018) investigated the relationship between PU and the desire to buy online. Given the 
importance of perceived utility in information technology adoption, this study proposes the following hypothesis:

H1 Perceived usefulness will have a significant effect on E-Entrepreneurship behavioral intention.

Social pressure in this study is used to determine whether or not there is a perceived pressure to engage in E-Entrepreneurship. An individuals' behavior may be influenced by social pressure in a variety of ways in various cultures, depending on the culture. Social pressure can be specifically influenced by a person's assumptions about what significant people think about their actions (Al-Maghrabi et al. 2011). Social pressure may be slightly important for E-Entrepreneurship behavioral purpose because entrepreneurship involves individual experiences (Shim et al. 2001). As a result, other researchers (Al-Maghrabi et al. 2011; Foucault et al. 2005) discovered a connection between social pressure and entrepreneurship. As a result, it is possible to speculate that:

H2 Social pressure will have a significant effect on E-Entrepreneurship behavioral intention

Online transactions are a metric that tracks E-Entrepreneurs' use of online platforms for buying and selling. Business channels, online and mobile platforms are expected to have a huge impact on people. DeLone and McLean (2004) looked into the performance of such systems and found that web/mobile platform quality combined the attributes of system quality, knowledge quality, service quality, user satisfaction, system usage, and net benefits. As a result, Online Transactions could have an effect on an entrepreneur's decision to pursue E-Entrepreneurship. This study found that the following hypothesis could be formed based on this scenario:

H3 Online transactions will mediate the relationship of perceived usefulness, social pressure with E-Entrepreneurship behavioral intention.

H4 Online transactions will have a significant effect on E-Entrepreneurship behavioral intention.

\section{Questionnaire development and sampling}

The instrument for data collection was a questionnaire which had two sections; the DEMATEL sections as well as the survey parts. The survey instrument and DEMATEL questions are both drafted from the adopted variables, using common wording rules for DEMATEL to signify "influence" while keeping the wording of questions as clear as possible, and for the survey to be as brief as possible.

The study's population was drawn from Saudi Arabia, for which DEMATEL and survey data were collected. Saudi Arabia has a population of about 40 million people. In Saudi Arabia, however, there has been a significant increase in the use of 
the Internet and e-commerce. Unfortunately, there are no comprehensive statistics on E-Entrepreneurship in Saudi Arabia. As a result, determining the exact population and calculating the sample size from people who own and use internet-enabled smartphones, PC's, or tablet PC's for entrepreneurship, was challenging for a researcher.

Burns et al. (2017) benchmarking was used to select the sample frame for this analysis, which consisted of Saudis who were engaged in an online company. According to this, a sample size of 96-384 people is considered appropriate for statistical power in data analysis. However, for DEMATEL, the number of sample experts should be between 5 and 10, as more than 10 experts' responses could result in a high degree of inconsistency, making the results unreliable (Tarei et al. 2018). Experts are described as those with an average of $80 \%$ industrial experience and $20 \%$ academic experience (Tarei et al. 2018). As a result, ten Saudi E-Entrepreneur experts have been chosen for the DEMATEL report. This research used a simple random sampling methodology for the survey method to ensure that every Saudi Arabian had a chance to participate. The participants are chosen entirely on the basis of their likelihood of participating in the study equally.

\section{Data collections and pilot test}

The data for this study was gathered through a self-administered quantitative survey that combined face-to-face and online (web-based) methods (Hair et al. 2016).

Face validity was assessed by research experts after pre-testing the survey and DEMATEL questions. Both are designed to evaluate the DEMATEL questions and survey instrument's suitability using a carefully selected sample (Hair et al. 2016). This allows you to see if the survey instrument contains any biased questions and if the respondents have any trouble understanding it. The questionnaire format, ambiguities, duration of the instrument, scale wording, and their general interpretation of the understanding of the terms used in the items are all checked and indicated by three research experts in this study. Their suggestions were implemented by rewording the queries, editing, clarifying, and removing the ambiguities, and the survey instrument was substantially updated, i.e., all of their suggestions were incorporated.

Following face validity and pretesting, a pilot test was conducted. This is critical in determining the content validity and reliability of the survey instrument, as well as determining whether the respondents understand all of the questions (Hair et al. 2016). Various researchers have differing views on the sample size that should be used in a pilot study to achieve sufficient reliability. Hair et al. (2016) contend that a sample size of $24-50$ is adequate for obtaining accurate results. As a result, respondents for the pilot study in this study were chosen from a wide range of backgrounds to ensure that all types of people were represented. As a result, 80 questionnaires were distributed, with 58 people completing and returning the instruments. There was no missing information in any of the results. The information was used to assess the survey instrument's validity.

According to the findings of the pilot study, males outnumbered females $70.8 \%$ to $29.2 \%$. With a response rate of $69.4 \%$, statistics revealed that respondents aged 
28-46 were particularly interested in the survey. Furthermore, those with a Bachelor's degree had the largest percentage of participants $(51.4 \%)$, followed by those with a diploma $(26.3 \%)$. The government (public) sector employed a large percentage of the participants (22.3\%), followed by workers in the private sector (22.4\%). A study was performed at this stage of pilot testing, and the results are shown below.

Cronbach's 'Alpha' is a test that determines how reliable the objects in the instrument are. Cronbach's 'Alpha' is strongest when it is close to 1.0. Cronbach's coefficients for all of the pilot study's variables were within reasonable ranges: behavior intention 0.815 , online transactions 0.806 , perceived usefulness 0.901 , and social pressure 0.888 . The final data collection was presented following the pilot analysis.

On the 13th of February 2019, 570 printed questionnaires were mailed to several groups of Saudis who engage in online transactions as part of the face-to-face data collection. Both the online and hardcopy questionnaires were collected by the deadline of August 2nd, 2019. A total of 322 responses were collected for both the online and hardcopy surveys. The data coding process began with assigning sequential numbers to the collected questionnaires in ascending order, beginning with online responses and ending with hardcopy responses. Finally, the data was cleaned up and ready to be analysed.

\section{Analysis and presentation of results}

The research objective determines the selection of the appropriate method of analysis, namely the examination, understanding and identification of the most significant factors affecting user-acceptation of E-Entrepreneurship in Saudi Arabia. This section presents the evaluation and testing of the research model being proposed using the data collected by the respondents in the field survey.

\section{Treatment of data integrity test}

Data intergity analysis involves verifying the missing value of the data input in the analytical tool. Data were processed to measure the items measuring the variables. Skewness and kurtosis are used for the normality test, the finding of the normality test for "perceived usefulness" which has five indicate that the mean score of this construct's items was rated between 4.03 (1.166) and 4.04 (1.171), while data normality values found between the acceptable range (less than \pm 2 ). Whereas, for "Online Transactions" which contains 8 items, the mean score was rated between $4.18(0.878)$ and $4.13(0.894)$ while the data normality values were found between the acceptable range (less than \pm 2 ). For "Social Pressure" which contains 5 items, the mean score of was found to be between 4.06 (1.038) and 4.16 (0.763) while the data normality values were found between the range (less than \pm 2 ). Finally, for behavior intention which contains six items, the mean score was found to be between $2.72(1.341)$ and $2.96(1.339)$ while the data normality values were found between the range (less than \pm 2 ). 


\section{Reliability and internal consistency}

Internal consistency measures how well the measure measures what it aims to measure. Understanding dependability is concerned with how accurately a procedure or mechanism delivers a certain quantity or result. An inexpensive and simple way to administer method of checking internal consistency is to conduct anonymous surveys. If the data gathered is a large amount it might give a variety of results in reality, which may complicate the issue of whether or not to establish consistency.

After examining the data integrity and determining that they meet all of the criteria for review, Cronbach's coefficients were used to determine the reliability and internal consistency. It was used again in the same way as in the pilot report. Each of the four major constructs has an alpha value between 0.71 and 0.90: "behavior intention 0.811", “online transactions 0.904", "perceived usefulness 0.879 ", and "social pressure 0.829 ".

To determine the sample's adequacy, an exploratory factor analysis was used. Since it is an appropriate measure for measuring sample adequacy, Kaiser-Meyer-Olkin (KMO) was used. For sample adequacy, a KMO value of $0.50-0.9$ is highly acceptable (Hair et al. 2016). Furthermore, the relevant value $(p)$ for Bartlett's test of sphericity results for sample adequacy must be $p 0.001$. The KMO value obtained in this analysis is 0.917, and Bartlett's Sphericity tests were found to be important at ( $p$ 0.001). Principal component analysis (PCA) was used to determine the number of factors to be retained, and variation maximum (varimax) rotation was used because it is the most common and effective orthogonal factor rotation approach for clarifying factor analysis. Finally, factor loadings with absolute values less than 0.5 were eliminated, leaving only objects with absolute values greater than 0.55 to be calculated (see Table 1).

\section{Analysis of the relationships among the variables}

After determining the strength of the relationship between constructs, the study of relationships among variables is used to test the hypothesis. The interrelationships between the variables are structured and modelled in order to decide how well the relationships fit or how well they fit together. As a result, Table 2 shows the effects of the correlations between the variables as well as the conclusions reached based on the hypothesis.

The parameter estimates were used to develop the estimated population covariance matrix, critical ratios, standardized estimates, and $p$ value used. To achieve a critical ratio (t-value), regression weight estimates divided by the standard error (S.E) was used. It assumed that a relationship is statistically significant at the 0.05 levels when the critical ratio (CR or $t$ value) was found higher than \pm 1.96 . The entire relationships were examined based on the strengths of the estimate relationships and CR ( $t$ values). The results demonstrated that $t$ values for the entire relationships are above the 1.96 (critical value) and significant at $p \leq 0.05$. 
Table 1 Rotated pattern matrix

\begin{tabular}{|c|c|c|c|c|}
\hline \multicolumn{5}{|c|}{ Rotated component matrix ${ }^{\mathrm{a}}$} \\
\hline & \multicolumn{4}{|c|}{ Component } \\
\hline & 1 & 2 & 3 & 4 \\
\hline OT66 & 0.797 & & & \\
\hline OT11 & 0.791 & & & \\
\hline OT7 & 0.746 & & & \\
\hline OT2 & 0.713 & & & \\
\hline OT43 & 0.699 & & & \\
\hline OT3 & 0.636 & & & \\
\hline OT5 & 0.622 & & & \\
\hline PU2 & & 0.791 & & \\
\hline PU4 & & 0.771 & & \\
\hline PU1 & & 0.721 & & \\
\hline PU6 & & 0.689 & & \\
\hline PU5 & & 0.677 & & \\
\hline PU3 & & 0.641 & & \\
\hline SP2 & & & 0.822 & \\
\hline SP3 & & & 0.783 & \\
\hline SP1 & & & 0.756 & \\
\hline SP6 & & & 0.726 & \\
\hline SP5 & & & 0.711 & \\
\hline SP4 & & & 0.699 & \\
\hline EB5 & & & & 0.877 \\
\hline EB1 & & & & 0.829 \\
\hline EB2 & & & & 0.801 \\
\hline EB4 & & & & 0.734 \\
\hline EB3 & & & & 0.699 \\
\hline
\end{tabular}

Table 2 Results of relationship test

\begin{tabular}{llllll}
\hline & Estimate & S.E & C.R & $p$ & Decision \\
\hline Social pressure $\rightarrow$ behavior intention & 0.451 & 0.068 & 6.582 & $* * *$ & Supported \\
Perceived usefulness $\rightarrow$ behavior intention & 0.273 & 0.062 & 4.369 & $* * *$ & Supported \\
Social pressure $\rightarrow$ online transaction & 0.214 & 0.068 & 3.162 & 0.002 & Supported \\
Perceived usefulness $\rightarrow$ online transaction & 0.53 & 0.062 & 8.549 & $* * *$ & Supported \\
Online transaction $\rightarrow$ behavior intention & 0.249 & 0.054 & 4.589 & $* * *$ & Supported \\
\hline
\end{tabular}

The parameter estimates are presented in Table 3, all the five hypothesized relationships among the variable are significant.

The analysis has indicated that all the hypotheses are positively significant and supported. This shows how strongly each predictor (variable) influences the criterion 
Table 3 Factor loadings and $t$ values for structural model

\begin{tabular}{|c|c|c|c|c|c|}
\hline Variables & $\begin{array}{l}\text { Hypothetical rela- } \\
\text { tionships }\end{array}$ & $\begin{array}{l}\text { Standardized } \\
\text { coefficient } \\
\text { weight }(\beta)\end{array}$ & $\begin{array}{l}\text { Unstandardized } \\
\text { coefficient weight } \\
(\beta)\end{array}$ & $t$ value & Decision \\
\hline Social pressure & $\mathrm{SP} \rightarrow \mathrm{BI}$ & 0.38 & 1.46 & $2.60 * *$ & Supported \\
\hline $\begin{array}{l}\text { Perceived useful- } \\
\text { ness }\end{array}$ & $\mathrm{PU} \rightarrow \mathrm{BI}$ & 0.57 & 0.35 & $4.87 * * *$ & Supported \\
\hline Social pressure & $\mathrm{SP} \rightarrow \mathrm{BI}$ & 0.91 & 2.04 & $2.62 * *$ & Supported \\
\hline $\begin{array}{l}\text { Perceived useful- } \\
\text { ness }\end{array}$ & $(\mathrm{PU}+\mathrm{SP}) \rightarrow \mathrm{OT}$ & 0.97 & 1.05 & $26.17 * * *$ & Supported \\
\hline Online transaction & $\mathrm{OT} \rightarrow \mathrm{BI}$ & 0.76 & 0.85 & $16.77 * * *$ & Supported \\
\hline
\end{tabular}

(variable) based on the $\beta$ value. Hence, the hypothesis testing results revealed that the values of critical ratio and standardized regression weight for all the variables are acceptable.

\section{Analysis of the key criteria by DEMATEL}

This section gives the results of the DEMATEL analysis, which was designed to uncover the main adoption criterion among the variables after analysing the correlations among the variables based on their psychometric measurement properties. As a result, the DEMATEL analysis is provided in the following steps:

The data of the 10 participants gathered during data collection of this part of the study was calculated to obtain their averages using Eq. 1 and presented in an average matrix $\boldsymbol{Z}$ below:

$\left[\begin{array}{cccc}0 & 3.172414 & 3.206897 & 3.166667 \\ 3.068966 & 0 & 3.035714 & 3.107143 \\ 3.035714 & 2.928571 & 0 & 2.923077 \\ 3.107143 & 2.928571 & 3.035714 & 0\end{array}\right]$

The matrix $\mathrm{Z}$ is normalized using Eq. 2 and present the result below:

$$
\left[\begin{array}{cccc}
0 & 0.332329818 & 0.335942098 & 0.331727771 \\
0.321492976 & 0 & 0.318009705 & 0.325492287 \\
0.318009705 & 0.306785833 & 0 & 0.30621025 \\
0.325492287 & 0.306785833 & 0.318009705 & 0
\end{array}\right]
$$

The total relation matrix $\boldsymbol{T}$ was calculated by using Eq. 3. This is the total causes and effects of the relationship among the criteria. The result is the presented in Table 4 below:

Similarly, the table provides the list of the criteria and their order of importance based on Eqs. 4a, 4b. Where it generates the sum of rows and columns of matrix T. Furthermore, the net effect by criteria is determined by Eq. 5 where $r+c$ values indicate the degree of important criterion stand. "Behavioral 
Table 4 The total relation matrix criteria

\begin{tabular}{llllll}
\hline & EB & PU & SP & OT & $\sum \mathrm{r}$ \\
\hline EB & 6.264007 & 6.419143 & 6.550225 & 6.504801 & 25.73818 \\
PU & 6.341857 & 6.006759 & 6.373653 & 6.336094 & 25.05836 \\
SP & 6.176863 & 6.0811 & 5.968568 & 6.162235 & 24.38877 \\
OT & 6.274273 & 6.172805 & 6.303467 & 6.020737 & 24.77128 \\
$\sum \mathrm{c}$ & 25.057 & 24.67981 & 25.19591 & 25.02387 & \\
\hline
\end{tabular}

Intention to adopt E-Entrepreneurs" criteria is the most important sub-criteria with the highest $r+c$ value, whereas "social pressure" criteria are the least important sub-criteria (see Table 5). The sign of the values of $r+c$ and $r-c$ reveal the level of the direct impact of criterion on other criteria, it can be positive or negative, when its positive it's a "cause", whereas when its negative is "affected" (see Table 5). Therefore, "Behavioral Intentions" and "Perceived Usefulness" of E-Entrepreneur are the positive "causal" criteria, whereas the rest are negative, which means they are the "affected" criteria.

To determine the order of importance by determining which criteria have the highest order of importance and which is the lowest, we set a threshold. The threshold was calculated by using Eq. 5. Therefore, the threshold value obtained which is the average of elements in matrix $\boldsymbol{T}$, is 6.247286637. As a result, only those values that are above the threshold are considered in the interrelationships impact assessment presented in Table 6.

Based on the threshold value, "behavioral intentions" directly impact and "social pressure" at 6.550225, which is the highest impact relation within those criteria, whereas the impact of "online transaction" on "behavioral intentions"

Table 5 The cause and effect criteria

Table 6 The interrelationships impact assessment

\begin{tabular}{llllcl}
\hline & $r$ & $c$ & $r+c$ & $r-c$ & Effect \\
\hline EB & 25.73818 & 25.057 & 50.79518 & 0.681176 & Cause \\
PU & 25.05836 & 24.6798 & 49.73816 & 0.378563 & Cause \\
SP & 24.38877 & 25.1959 & 49.58467 & -0.80713 & Affected \\
OT & 24.77128 & 25.0239 & 49.79518 & -0.25262 & Affected \\
\hline
\end{tabular}

\begin{tabular}{lllll}
\hline & EB & PU & SP & OT \\
\hline EB & $\mathbf{6 . 2 6 4 0 0 7}$ & $\mathbf{6 . 4 1 9 1 4 3}$ & $\mathbf{6 . 5 5 0 2 2 5}$ & $\mathbf{6 . 5 0 4 8 0 1}$ \\
PU & $\mathbf{6 . 3 4 1 8 5 7}$ & 6.006759 & $\mathbf{6 . 3 7 3 6 5 3}$ & $\mathbf{6 . 3 3 6 0 9 4}$ \\
SP & 6.176863 & 6.0811 & 5.968568 & 6.162235 \\
OT & $\mathbf{6 . 2 7 4 2 7 3}$ & 6.172805 & $\mathbf{6 . 3 0 3 4 6 7}$ & 6.020737 \\
\hline
\end{tabular}

The values in bold represent those values that are above the threshold. Hence they are indicators of the interactions relationships that represent high priority 
Fig. 1 The entire impact interrelationships

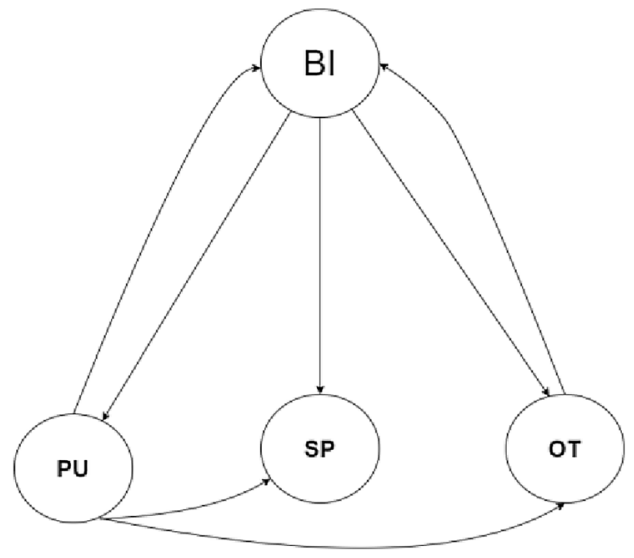

is the least within the entire interrelationships. The entire impact relationship is presented in Fig. 1.

\section{Interpretation of the results}

This result demonstrated that the variables' relationships are statistically important. As a result, "perceived usefulness" and "social pressure" have a big impact on "E-Entrepreneurship behavioral intention". The relationship between perceived usefulness, social pressure, and "E-Entrepreneurship behavioral intention" is mediated by "Online Transactions". Finally, "Online Transactions" have a huge impact on the behavioral intention of E-Entrepreneurs. The user's perception related to E-Entrepreneurship has been examined by empirical results which support the argument that usefulness beliefs of the potential users have a positive impact on the behavioral intention to adopt E-Entrepreneurship. These findings are in line with the findings of the original TAM, which found that PU has a major impact on behavior intention (Davis 1989). Many empirical studies in the field of IS/IT acceptance (Abbasi et al. 2010; Abdelkarim and Nasereddin 2010; Chandio 2011; Chan and Lu 2004; Davis 1989; Eunju and Kyung 2009; Jen et al. 2009; Moorty et al. 2014; Pai and Huang 2011; Pikkarainen et al. 2004; Sun et al. 2014) DEMATEL's findings are also consistent with this. It shows that "Behavioral Intentions" to follow E-Entrepreneurship, are a crucial criterion, with the highest score of any criterion and the greatest direct effect on "Perceived Usefulness".

These empirical findings imply that Saudis are compelled to accept E-Entrepreneurship because of their opinions about its relative advantages, after analyzing its usefulness. As a result, if the value of E-Entrepreneurship is recognized by potential users, it is more likely to be accepted on a big scale in Saudi Arabia. In conclusion, the findings of this study showed that the usefulness construct plays a crucial role in predicting users' behavioral intention to accept 
E-Entrepreneurship. Social Pressure is the important criteria that have the highest order of importance in the impact relationships within the four criteria.

\section{Discussion}

This research presents a study of the impact of E-Entrepreneurs' adoption as a new service or system within the information systems area, where its practical use is deemed to be extremely important. Many researchers (Algethmi 2014; Chandio 2011; Gu et al. 2009; Mathieson et al. 2001) claim that research studies examining the elements influencing a customer's behavioral intention to adopt a new IS/IT system or service through TAM, typically utilise "intention to use" as a dependent variable rather than "actual use". Because the primary goal of this research was to look at the factors that influence acceptance of E-Entrepreneurship, rather than actual use, the dependent variable was "behavioral intention to use." Furthermore, because the PEOU and PU constructs in the original TAM are directly dependent on BI rather than actual use, several research papers (Algethmi 2014; Chandio 2011; Gu et al. 2009; Gefen and Straub 2000; Jarvenpaa et al. 2000; Shih and Fang 2004) empirically examined IS/IT system and service acceptance using BI as a dependent variable. The general relationship between the predictor variables (independent variables) and the outcome variable, i.e. behavioral intention to use, was measured in this study using a hypothesized proposed research model, in comparison to Younis et al. (2020) — the study on the effects of E-Entrepreneur adoption in Qatar. It was discovered that social and cultural perspectives influence attitudes toward digital entrepreneurship. Even though Qatar and Saudi Arabia have similar cultural heritages, this is not the case in Saudi Arabia.

According to the findings of the study, PU and SP were the direct predictors of E-Entrepreneurship adoption in Saudi Arabia. Two indirect hypothesized associations between OT and (PU-SP) and BI, on the other hand, were shown to be significant. Each of the constructs is regarded as critical to the application and adoption of E-Entrepreneurship. Overall, the variables investigated in determining the E-Entrepreneurship acceptance model have been discovered.

This study adds to the idea of TAM by developing and testing a theoretical framework for how E-Entrepreneurship develops internal capabilities as a key driver for developing Saudi Arabia's E-Entrepreneurship. Although TAM does not give the complete framework for what this study provided, other essential aspects such as "social pressure" and "online transactions" contribute to the production of new dimensions to this study and provide an explanation of how E-Entrepreneurship develops at both individual and organizational levels. The essential criteria and variables that influence Entrepreneurship adoption, but not E-Entrepreneurship, have empirical evidence in the literature. The elements that influence E-Entrepreneurship adoption were discovered by combining the two variables (social pressure and online transaction) with the TAM variables.

The research model stated that E-Entrepreneurship practices at the online transaction level, generate outcomes and that Saudis should investigate its potential. 
This study bridges the theoretical and practical debates by demonstrating the utility of the complicated inimitable notions that are embedded in E-Entrepreneurship adoption. In addition, the study adds to the theory by examining the interactions between OT, SP, and PU in a combined model. This integration emphasizes the role of E-Entrepreneurship in the generation and mobilization of information. The knowledge gained and developed as a result of E-Entrepreneurship acceptance is used to establish a new service. Cultural differences between Western nations and Saudi Arabia, according to the report, are a concern that can hinder E-Entrepreneurship.

The study's methodological contribution is based on unidimensional measurements; however, this study employs a broad measure of E-Entrepreneurship as well as a multidimensional measure of behavioral intention. The analytical methodology employed allows for a thorough and simultaneous evaluation of the measurement features of the constructs operationalized in this study, resulting in reliable statistical evidence for the numerous analyses conducted.

The practical contributions, consequences, and recommendations give important information for potential E-Entrepreneurs in Saudi Arabia who want to boost their bottom line by utilizing the benefits of the information-based economy. It is projected that in the future, Saudis who want to grow their firm will need to develop and increase their abilities to use E-Entrepreneurship. This is particularly important for Saudis who want to work in the technology-driven industry of E-Entrepreneurship. Several recommendations are given in light of this implication. Saudi Arabia could encourage the growth of new E-Entrepreneurship by empowering themselves and developing new concepts. The Saudi Arabian government can also promote a culture of empowering E-Entrepreneurship. For example, informal procedures might be established to facilitate the exchange of E-Entrepreneurship best practices. Teamwork is another crucial aspect of E-Entrepreneurship, since it allows Saudis to openly interact and exchange ideas when working on a specific E-Entrepreneurship. Additionally, Saudi Arabian business leaders must foster an environment of openness and experimentation. This can be accomplished by providing resource-based assistance for E-Entrepreneurship ideas.

\section{Limitations and recommendations for future research}

This research focuses on the key enabling criteria of E-Entrepreneurship that have evolved over time, as well as the practices and implementation of E-Entrepreneurship in Saudi Arabia. The fundamental criterion for "Behavioral Intention" to adopt E-Entrepreneurship is determined to be "Perceived Usefulness" of E-Entrepreneurship. However, this study only analyses individual levels and does not address the issue of numerous E-Entrepreneurship demand services and applications for enterprises. Future research could pinpoint the types of E-Entrepreneurship demand services and applications for businesses, as well as determine whether or not a company can entirely rely on online or E-Entrepreneurship-based services. Furthermore, the scope of this research is limited to the impact of adoption techniques in the realm of E-Entrepreneurship activities by 
businesspeople. Employees who engage in E-Entrepreneurship as a second job, however, have a slew of other difficulties. As a result, future studies should investigate defining E-Entrepreneurship as a full-time job or a part-time job. Crossnational studies on many aspects of E-Entrepreneurship should be done as well. This will confirm the validity of the proposed framework as well as the findings' differences. As a result, generalizability of the results of this type of study can be established across various business systems and organizational structures.

\section{Conclusion}

This research provides new empirical evidence on the state of E-Entrepreneurship in Saudi Arabia and how online businesses are completely performed on the Internet. This is critical because it is currently the fastest-growing market. To improve and create greater prospects for entrepreneurship development, several places throughout the world employ online enterprises. Saudi Arabians who started Internet businesses are the primary respondents in this study. Despite the fact that there are several research papers from many contexts that demonstrate the importance of E-Entrepreneurship, E-business Entrepreneurship's effects and potential were not substantially examined until recently. As a result, for the complexity and dynamic flow-process of E-Entrepreneurship, this study uses an online platform as the basis of participation. The study examines the E-Entrepreneurship platform, which encourages people to participate in the creation of innovative business models. It is critical to ensure the necessary requirements for increasing the adoption of E-Entrepreneurship as a business model, as well as to identify the important variables. As a result, the purpose of this research was to see how Saudi Arabians viewed E-Entrepreneurship. Quantitative research methodology is used because it uses hypothesis testing to draw findings from a theory inductively. This method collects data on tightly defined variables using standardized instruments. "E-entrepreneurship behavioral intention (EBI)", "perceived usefulness (PU)", "social pressure (SP)", and "online transactions (OT)" were identified as the four primary variables. The study's sample was gathered in Saudi Arabia.

An examination of the relationships between the variables is conducted. All of the hypotheses are positively significant and supported, according to the data. This shows how the variables E-Entrepreneurship Behavioral Intention have an impact. The research identifies the critical aspects that influence E-Entrepreneurship acceptability in Saudi Arabia. The study's findings have important implications for E-Entrepreneurship service providers and e-marketers who want to gain a better knowledge of the factors that influence an individual's willingness to adopt E-Entrepreneurship.

Supplementary Information The online version contains supplementary material available at https://oi. org/10.1007/s43546-021-00110-4. 
Data availability Any data analysed are included in the paper.

\section{Declarations}

Conflicts of interest There is no conflict of interest.

Ethical standards All procedures performed in studies involving human participants were in accordance with the ethical standards of the King Abdul-Aziz University Saudi Arabia research committee and with the 1964 Helsinki declaration and its later amendments or comparable ethical standards.

\section{References}

Abbasi MS, Irani Z, Chandio FH (2010) Determinants of social and institutional beliefs about internet acceptance within developing country's context: a structural evaluation of higher education systems in Pakistan

Abdelkarim A, Nasereddin H (2010) Mobile commerce. J Math Technol 4(1):51-56

Abubakar AI, Chiroma H, Muaz SA, Ila LB (2015) A review of the advances in cyber security benchmark datasets for evaluating data-driven based intrusion detection systems. Proc Comput Sci 62:221-227

Abubakar AI, Mohamed EEE, Zeki AM (2017) The dynamics of data packet in transmission session. IEEE Access 5:4329-4339

Ajzen I (1991) The theory of planned behavior. Organ Behav Hum Decis Process 50(2):179-211

Ali MA, Hoque MR, Alam K (2018) An empirical investigation of the relationship between e-government development and the digital economy: the case of Asian countries. J Knowl Manage 22(5):1176-1200

Al-Maghrabi T, Dennis C, Halliday SV (2011) Antecedents of continuance intentions towards e-shopping: the case of Saudi Arabia. J Enterprise Inf Manage24(1):85-111

Asadollahi Kheirabadi M, Rafieian J (2019) A review of e-entrepreneurship in the net economy and its economic impacts. Journal of Humanities Insights 3(04):217-221

Ayough A, Alemtabriz A, Tavanaei M (2020) Investigating the impact of technological distinctive competencies and information technology capabilities on internet entrepreneurship by means of innovation capability. AMC Indian J Entrepreneur 3(1):27-41

Ballı A (2020) Digital entrepreneurship and digital entrepreneurship approach in Turkey: Ankara case. İşletme Araştırmaları Dergisi 12(2):1058-1071

Burns MD, Monteith MJ, Parker LR (2017) Training away bias: The differential effects of counterstereotype training and self-regulation on stereotype activation and application. J Exp Social Psychol 73:97-110

Chandio FH (2011) Studying acceptance of online banking information system: A structural equation model (Doctoral dissertation, Brunel University Brunel Business School PhD Theses)

Chen YS (2019) E-entrepreneurship and innovation in franchising. Int J E-Entrepreneur Innov (IJEEI) $9(1): 1-12$

Curty RG, Zhang P (2013) Website features that gave rise to social commerce: a historical analysis. Electron Commerce Res Appl 12(4):260-279

Dayal S (2016) An Analysis of the Social Media Influence on the online buying behavior of Indian Consumers, XVII Annual International Seminar Proceedings

Davis FD (1989) Perceived usefulness, perceived ease of use, and user acceptance of information technology. MIS Quarterly 319-340

DeLone WH, McLean ER (2004) Measuring e-commerce success: applying the DeLone \& McLean information systems success model. Int J Electron Comm 9(1):31-47

Eliakis S, Kotsopoulos D, Karagiannaki A, Pramatari K (2020) Survival and growth in innovative technology entrepreneurship: a mixed-methods investigation. Adm Sci 10(3):39

Farooque M, Jain V, Zhang A, Li Z (2020) Fuzzy DEMATEL analysis of barriers to Blockchain-based life cycle assessment in China. Comput Ind Eng 147:106684 
Foucault T, Kadan O, Kandel E (2005) Limit order book as a market for liquidity. Revi Finan Stud 18(4):1171-1217

Friedrich T (2015) Analyzing the Factors that Influence Consumers' Adoption of Social Commerce-A Literature Review. Twenty-first Americas Conference on Information Systems, Puerto Rico

Gu JC, Lee SC, Suh YH (2009) Determinants of behavioral intention to mobile banking. Expert Systems Appl 36(9):11605-11616

Hair JF Jr, Sarstedt M, Matthews LM, Ringle CM (2016) Identifying and treating unobserved heterogeneity with FIMIX-PLS: part I-method. Eur Bus Rev

Huang J, Baptista J, Galliers RD (2013) Reconceptualizing rhetorical practices in organizations: the impact of social media on internal communications. Inf Manage 50(2-3):112-124

Jarvenpaa SL, Tractinsky N, Vitale M (2000) Consumer trust in an Internet store. Inf Technol Manage 1(1-2):45-71

Jen W, Lu T, Liu PT (2009) An integrated analysis of technology acceptance behaviour models: Comparison of three major models. MIS REVIEW Int J 15(1):89-121

Jiang S, Shi H, Lin W, Liu HC (2020) A large group linguistic Z-DEMATEL approach for identifying key performance indicators in hospital performance management. Appl Soft Comput 86:105900

Kim Y (2006) Study on impact mechanism for beef cattle farming and importance of evaluating agricultural information in Korea using DEMATEL, PCA and AHP. Agric Inf Res 15(3):267-279

Kollmann T (2014) What is E-Entrepreneurship? Fundamentals of company founding in the net economy. In: Handbook of research on techno-entrepreneurship, 2nd edn. Edward Elgar Publishing, Cheltenham

Lai LS, To WM (2020) E-Entrepreneurial intention among young Chinese adults. Asian J Technol Innov 28(1):119-137

Lee YC, Li ML, Yen TM, Huang TH (2010) Analysis of adopting an integrated decision making trial and evaluation laboratory on a technology acceptance model. Expert Syst Appl 37(2):1745-1754

Liang TP, Ho YT, Li YW, Turban E (2011) What drives social commerce: The role of social support and relationship quality. Int J Elect Comm 16(2):69-90

Liou JJH, Yen L, Tzeng GH (2008) Building an effective safety management system for airlines. J Air Transp Manag 14(1):20-26

Mand HS, Atri M, Gill A, Amiraslany A (2018) The impact of bank financing and internal financing sources on women's motivation for e-entrepreneurship. Int J Gender Entrepreneur

Mathieson K, Peacock E, Chin WW (2001) Extending the technology acceptance model: the influence of perceived user resources. ACM SIGMIS Database: DATABASE Adv Inf Syst 32(3):86-112

Moorthy MK, Samsuri ASB, Hussin SBM, Othman MSB, Chelliah MK (2014) E-filing behaviour among academics in Perak State in Malaysia. Technol Invest 5(2):45826. https://doi.org/10.4236/ti.2014. 52009

Pai FY, Huang KI (2011) Applying the technology acceptance model to the introduction of healthcare information systems. Technol Forecast Soc Change 78(4):650-660

Pikkarainen T, Pikkarainen K, Karjaluoto H, Pahnila S (2004) Consumer acceptance of online banking: an extension of the technology acceptance model. Int Res 14(3):224-235

Rahmi S, Fauziati P, Harahap EF, Novianti N, Puttri D (2020) Analysis of e-commerce and E-Entrepreneurship challenges on digital economic development in west Sumatra in supporting national economic GROWTH. Humanit Soc Sci Rev 8(2):808-814

Rostamnezhad M, Nasirzadeh F, Khanzadi M, Jarban MJ, Ghayoumian M (2020) Modeling social sustainability in construction projects by integrating system dynamics and fuzzy-DEMATEL method: a case study of highway project. Eng Cons Arch Manage. https://doi.org/10.1108/ecam-01-2018-0031

Sheng-Li S, Xiao-Yue Y, Hu-Chen L, Zhang P (2018) DEMATEL technique: a systematic review of the state-of-the-art literature on methodologies and applications. Math Probl Eng

Shih YY, Fang K (2004) The use of a decomposed theory of planned behavior to study Internet banking in Taiwan. Int Res 14(3):213-223

Shim S, Eastlick MA, Lotz SL, Warrington P (2001) An online prepurchase intentions model: the role of intention to search: best overall paper award - the sixth triennial AMS/ACRA retailing conference, 2000岤 1. J Retail 77(3):397-416

Sun Y, Liu L, Peng X, Dong Y, Barnes SJ (2014) Understanding Chinese users' continuance intention toward online social networks: an integrative theoretical model. Elect Mark 24(1):57-66

Tarei PK, Thakkar JJ, Nag B (2018) A hybrid approach for quantifying supply chain risk and prioritizing the risk drivers. J Manuf Technol Manag 
Tsai WH, Chou WC (2009) Selecting management systems for sustainable development in SMEs: a novel hybrid model based on DEMATEL, ANP, and ZOGP. Expert Syst Appl 36(2P1):1444-1458

Tseng ML (2009) A causal and effect decision making model of service quality expectation using greyfuzzy DEMATEL approach. Expert Syst Appl 36(4):7738-7748

Venkatesh V, Morris MG, Davis GB, Davis FD (2003) User acceptance of information technology: toward a unified view. MIS Quart 425-478

Wang C, Zhang P (2012) The evolution of social commerce: the people, management, technology, and information dimensions. Commun Associ Inf Syst 31(1):5

Wei PL, Huang JH, Tzeng GH, Wu SI (2010) Causal modeling of web advertising effects by improving SEM based on DEMATEL technique. Int J Inf Technol Decis Mak 9(5):799-829

Wu WW, Lee YT (2007) Developing global managers' competencies using the fuzzy DEMATEL method. Expert Syst Appl 32(2):499-507

Younis H, Katsioloudes M, Al Bakri A (2020) Digital entrepreneurship intentions of Qatar university students motivational factors identification: digital entrepreneurship intentions. Int $\mathbf{J}$ E-Entrepreneurship Innov (IJEEI) 10(1):56-74

Zhou L, Zhang P, Zimmermann HD (2013) Social commerce research: an integrated view. Electron Commer Res Appl 12(2):61-68 